\title{
Preference for signaled shock: A test of two hypotheses
}

\author{
JANE M. ARABIAN and OTELLO DESIDERATO \\ Connecticut College, New London, Connecticut 06320
}

\begin{abstract}
In a test of safety signal and preparatory response explanations of the preference for signaled vs. unsignaled shock, three groups of rats were exposed to a different light-tone-shock contingency on each of the two sides of a shuttlebox. One contingency (S/P) provided both a safety signal and a warning stimulus, another (NS/NP) provided neither, and a third (S/NP) provided a safety period but no warning stimulus. Rats preferred either the $S / P$ or the $S / N P$ side of the shuttlebox when the alternate side provided neither safety signal nor warning stimulus. When the safety signal was available on both sides, the side without the warning stimulus was preferred. Results are interpreted as supporting the safety signal hypothesis.
\end{abstract}

Data from both human (Lanzetta \& Driscoll, 1966) and animal (Badia, Culbertson, \& Lewis, 1971) subjects have shown that, given the choice, organisms will act to produce stimuli which signal the imminence of a painful event. The stress-reducing effect of such stimuli is inferred from data which show that exposure to signaled, but inescapable, shock produces fewer psychosomatic reactions than does exposure to equivalent but unsignaled shock (Seligman, 1968; Weiss, 1970). Preference for signaled shock has given rise to two interpretations: (a) the preparatory response hypothesis, which holds that a warning signal permits the animal to make some type of preparatory response, either peripheral or central, which has the effect of reducing the aversiveness of the shock (Perkins, 1968); and (b) the safety signal hypothesis, which asserts that the absence of the signal is the crucial factor, since this condition is reliably correlated with the absence of shock. Signal offset, therefore, initiates a shock-free period of safety, during which the animal's fear level is assumed to decline (Lockard, 1963; Seligman, 1968).

In the typical signaled-shock paradigm used in most spatial preference studies (Perkins, Seymann, Levis, \& Spencer, 1966), the same preshock stimulus could be viewed either as a warning signal evoking a preparatory response, as a cue discriminating periods of safety from periods of danger, or both. A less frequently employed interpretation of the role of the preshock stimulus is that it becomes a Pavlovian fear elicitor, since it is consistently paired with shock. There is ample evidence that escape from Pavlovian CSs for shock is reinforcing (Kalish, 1954; McAllister \& McAllister, 1962). In the typical preference study, the signaled-shock side of a shuttlebox may be preferred for its periods of safety. These may be sufficiently fear

This research was completed while the first author was an undergraduate participant in the NSF Research Participation Program at Connecticut College. The authors appreciate the assistance of George Bittlingmayer and Sue Maunders in the conduct of this study. Jane M. Arabian is now at the University of Toronto. Requests for reprints should be sent to Otello Desiderato, Department of Psychology, Connecticut College, New London, Connecticut 06320. reducing to override the feareliciting properties of the CS.

The present study attempted to separate the effects of a safety signal and a preparatory or warning stimulus. The design called for exposing each of three groups of rats to a different light-tone-shock contingency on the two sides of a shuttlebox, with side-preference tests interspersed throughout the training. The first contingency (S/P) defined both a safety signal and a preparatory stimulus. In this condition, shocks never occurred when the light CS was off (safety signal), and shocks occurring in the presence of the light were always signaled by a 5 -sec tone CS (preparatory stimulus).

In the second condition (S/NP), preparatory responses were precluded, since tones and shocks were randomly related. Since shocks occurred only in the presence of the light, darkness again defined the period of safety. Both safety signal and preparatory stimulus were eliminated in the third contingency (NS/NP), by having tones and shocks occur independently of each other, regardless of whether the light was on or off.

\section{METHOD}

\section{Subjects}

The subjects were 24 male rats of the Sprague-Dawley strain. At the start of the experiment, they were between 2 and 4 months old and their weights ranged between 340 and $590 \mathrm{~g}$. They were individually housed and maintained on ad-lib water and a Purina Lab Chow diet throughout the study.
Apparatus
Four experimental chambers, each $60 \times 16 \times 15 \mathrm{~cm}$, were divided into two equal compartments-one painted flat black, the other gray. A removable partition used to confine the subjects to one side of the box was also painted black on one side and gray on the other. The floor of each chamber consisted of stainless steel grids $3 \mathrm{~mm}$ in diam, spaced $13 \mathrm{~mm}$ apart. Scrambled shock, generated by a Grason-Stadler Model 700 shock source, was delivered to the floor grids of all chambers, which had been wired in series. A white 7-W incandescent bulb attached to the Plexiglas cover of each compartment served as the long light stimulus. A $12-\mathrm{cm}$ speaker, used to deliver 5-sec $1,000-\mathrm{Hz}$ tone stimuli, was also mounted on the Plexiglas cover of each box. A $25-\mathrm{cm}$ speaker, located in a corner of the experimental room, was used to deliver white masking noise. 

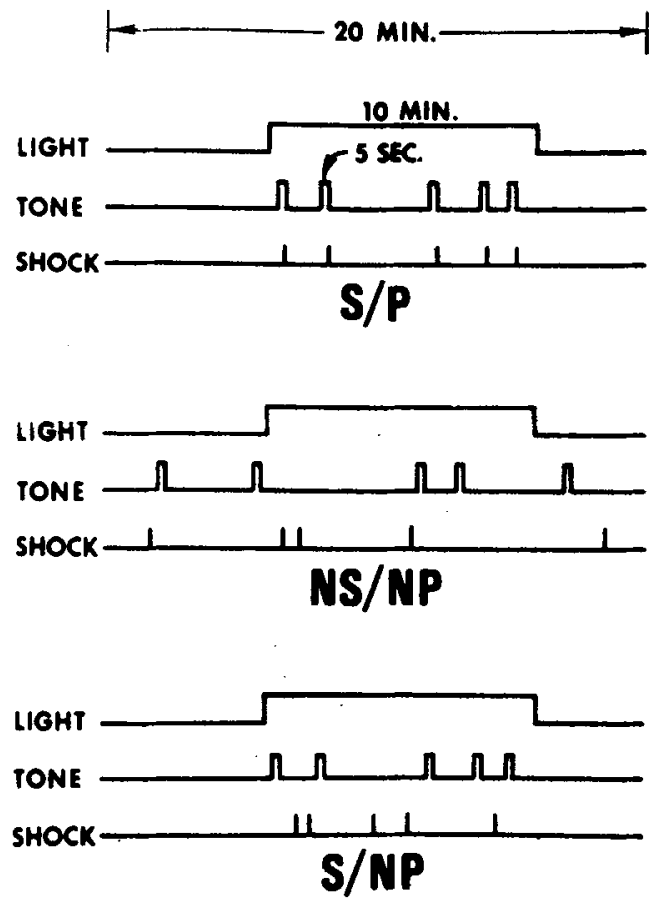

Figure 1. Three paradigms in which contingencies between light, tone, and shock stimuli are varied. In the S/P condition, light absence is a safety signal, and the tone is a preparatory stimulus. In condition NS/NP, no safety signal or preparatory stimulus is available. In condition $S / N P$, light absence is the safety signal but no preparatory stimulus is available.

During side-preference tests, clocks were used to record the total amount of time the subjects spent on each side of the chamber.

\section{Procedure}

In order to vary independently the safety signal and preparatory response properties of the stimuli employed, three light-tone-shock contingencies were established. In the safety-preparatory response contingency $(\mathrm{S} / \mathrm{P})$, shocks were never delivered when the light was off. During 10-min light-on periods, shocks occurred randomly, but each shock was preceded by the 5 -sec tone CS (preparatory stimulus). It was assumed that $5 \mathrm{sec}$ would be sufficient time for some preparatory response to occur. Since the light discriminated a period of danger, it was further assumed that the light would not function as a fear inhibitor, even when the tone CS was not present. Thus, since darkness was positively correlated with safety and the tone preceded each shock, the $S / P$ contingency contained both a safety signal and the $C S$ for a preparatory response. The S/P paradigm is illustrated in the top portion of Figure 1.

In paradigm NS/NP, shown in the middle of Figure 1, there is no safety signal since light offset does not predict a shock-free period. Moreover, since tones and shocks occur independently, tone onset would not be expected to evoke a preparatory response. Finally, Figure 1 shows paradigm $\mathrm{S} / \mathrm{NP}$, in which darkness is a reliable safety signal, but the tone, occurring independently of shock, would still not be expected to evoke a preparatory response.

After an initial habituation day during which the training procedures described below were followed, but no shock was administered, 10 consecutive daily sessions were held. On each day, every rat was confined for a $20-\mathrm{min}$ period on each side of the shuttlebox, with one paradigm in effect on one side and a different paradigm on the other side. To observe the preference for the condition containing both safety signal and preparatory response features, one group of eight rats (Group A) was exposed to the $S / P$ paradigm on one side and the NS/NP paradigm on the other side of the shuttlebox. To assess the effect of the safety signal in the absence of opportunities for making a preparatory response, eight rats assigned to Group B were exposed to the S/NP condition on one side and the NS/NP condition on the other. In a direct test of the effect of the preparatory stimulus (Tone CS), eight rats assigned to Group $\mathrm{C}$ were exposed to the $\mathrm{S} / \mathrm{P}$ condition on one side and $\mathrm{S} / \mathrm{NP}$ condition on the other side. For this group, the safety signal was provided on both sides. The duration of all shocks was $.5 \mathrm{sec}$, and the intensity $2.0 \mathrm{~mA}$. Regardless of group assignment or contingency condition, all subjects received five tones, five shocks, and one light presentation per 20-min confinement period.

Each daily session began with a 10-min period of free exploration within the shuttlebox, during which the partition was removed and no stimuli were delivered. The subjects were then confined to either the gray or the black side of the box for $20 \mathrm{~min}$ during which the appropriate light-tone-shock contingency was in effect. The subjects were then confined for another $20 \mathrm{~min}$ to the other side of the box, where they were exposed to the alternate contingency appropriate to their group. Regardless of group assignment or contingency condition, all subjects received five tones, five shocks, and one 10 -min light stimulus during each 20 -min confinement period. To control for color of box, for half the subjects in each group, exposure to one set of contingencies occurred on the black side of the shuttlebox; for the remaining subjects, exposure to the same contingency condition occurred on the gray side.

The first preference test followed immediately: the partition was removed, and the rat was placed in the center of the box and allowed to move freely, while the time it spent on each side was recorded. During the first 10 -min test, neither light, tone, nor shock stimuli were presented. After the test, the subjects were removed from the shuttlebox, the partition was replaced, the subject was confined to the same side it had been in before the test, and the entire training and test procedure was repeated. During the second $10-\mathrm{min}$ test, tones and shocks were again omitted, but the light stimulus remained on for the entire $10 \mathrm{~min}$. A small desk lamp provided enough illumination to permit the experimenter to record, after every test trial, the time each subject had spent on each side and, at the end of every session, the number of boluses found under each shut tlebox.

All subjects were weighed on the 1 st day, just prior to the habituation session, and again just prior to the last experimental session.

\section{RESULTS}

For each subject, the mean of 20 observations (two for each experimental day) of time spent on each side of the shuttlebox was computed. The results of the preference tests for 10 experimental days are shown in Figure 2. Subjects in Group A, which were exposed to $\mathrm{S} / \mathrm{P}$ contingencies on one side and NS/NP contingencies on the other side of the shuttlebox, spent an average of $72 \%$ of their time on the S/P side. Every subject in this group showed a preference for the $S / P$ side over the 10 days; moreover, every subject preferred the $\mathrm{S} / \mathrm{P}$ side everyday beginning with Day 6 . Two-tailed use of the binomial test showed these results to be significant at $p=.008$.

Figure 2 also shows that when the preparatory stimulus was omitted from the side on which the 
darkness served as a safety signal, subjects spent $82 \%$ of the time on the S/NP sice. The binomial test applied to Group B revealed the same results as for Group A, except that every subject in Group B spent more than $50 \%$ of its time on the S/NP side beginning with Day 4. Group $C$, which experienced darkness as a safety signal on both sides of the shuttlebox, revealed a pronounced preference for the side on which the tone did not reliably predict shock. Mean time spent on the S/NP side was $82 \%$. Application of the binomial test yielded the same results as for Group B.

Time spent on the $\mathrm{S} / \mathrm{P}$ side (Group $\mathrm{A}$ ) was compared with time spent on the S/NP side (Group B), since these two groups were exposed to identical conditions (NS/NP) on the alternate side. Although the tone did not serve as a preparatory stimulus in Group B, this group spent more time ( $82 \%$ ) on the side associated with the safety signal (S/NP) than did Group A (72\%), which had both safety and preparatory signals on the preferred side. The difference, however, was only marginally reliable $(t=1.95, \mathrm{df}=14, \mathrm{p}<.10)$.

Groups $\mathrm{A}$ and $\mathrm{C}$ both had a safety signal and $\mathrm{a}$ preparatory stimulus on one side of the shuttlebox, but only in Group $\mathrm{C}$ was the safety signal also present on the alternate side of the box. Time spent on the $S / P$ side by Group C (18\%) was significantly lower than the time spent on the $\mathrm{S} / \mathrm{P}$ side $(72 \%)$ by Group A $(t=2.98$, df $=14, p<.01$ ).

Figure 3 shows the development of side preferences over the course of 10 experimental days. Group means were not significantly different on the habituation day, nor on Day 1, the Ist experimental day. By Day 4, Groups A and B both displayed a distinct preference for the side containing the safety signal, rather than the NS/NP side. Analysis of variance applied to the time scores recorded for Groups A and B across 10 days revealed a stronger preference for the $S / N P$ side in Group B than for the S/P side in Group A $(F=5.98$,

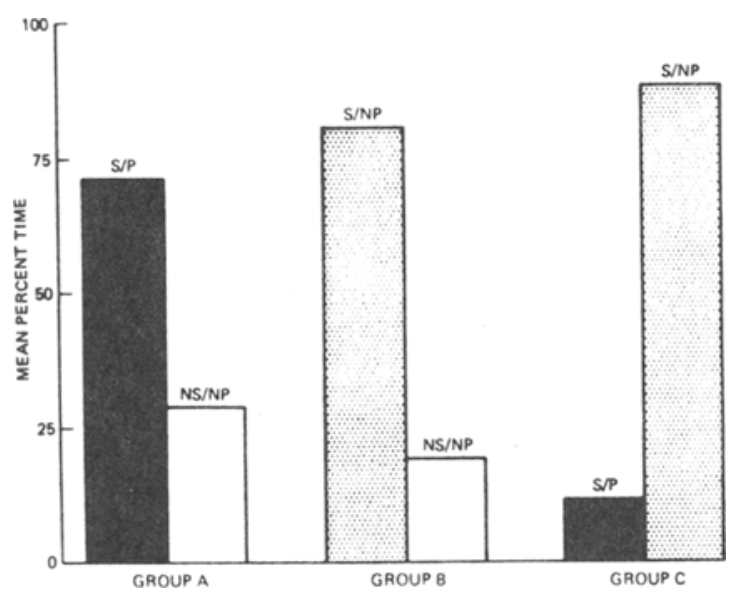

Figure 2. Mean percent time spent on each side of the shuttlebox by Groups A, B, and C.

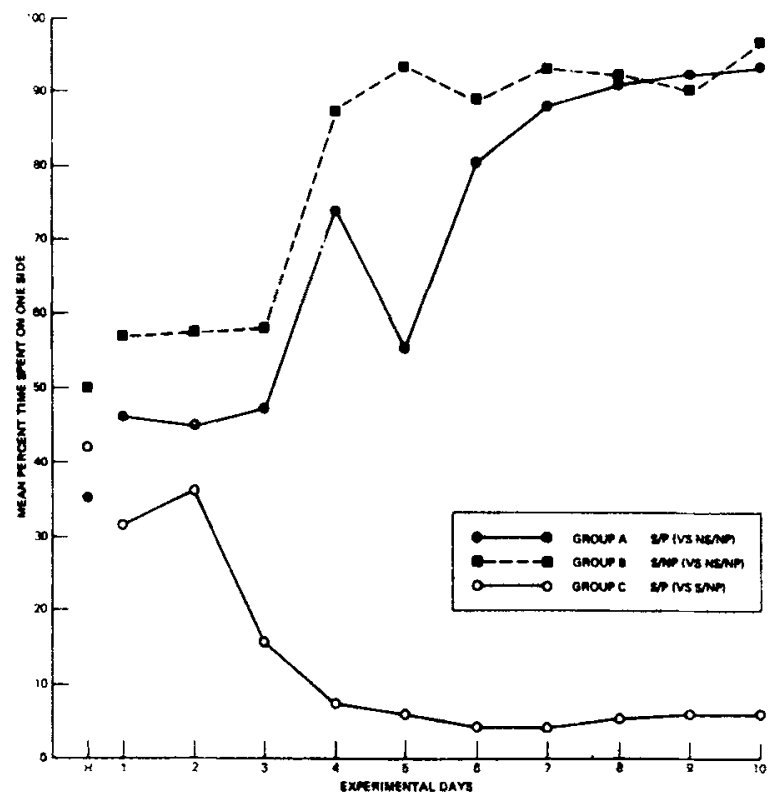

Figure 3. Mean percent time spent on the $S / P$ side (Groups $A$ and $C$ ) and on the $S / N P$ (Group $B$ ) on each experiment day.

$\mathrm{df}=1 / 14, \mathrm{p}<.05)$. The main effect for Days, but not the Groups by Days interaction, was significant $(F=12.98, \mathrm{df}=9 / 124, \mathrm{p}<.001)$.

Preference for the S/P side over days diminished in Group C, while preference for the same side increased in Group A, yielding a significant Groups by Days interaction $(F=13.66, d f=9 / 124, p<.001)$. Similar results were obtained when Groups $B$ and $C$ were compared across days. Additional analyses revealed that neither the color of the compartment walls nor the presence or absence of the light stimulus during the daily preference tests significantly affected side preferences.

Analysis of variance applied to bolus counts recorded at the end of each subject's daily session revealed a progressive decline across experimental days $(F=3.36$, $\mathrm{df}=9 / 162, \mathrm{p}<.001)$, but significant group differences were also found $(F=6.43, d f=2 / 18, p<.01)$. Despite no initial differences in defecation measures, Group B, the only group in which no preparatory stimulus was available on either side, produced the lowest mean number of boluses (67.9), compared with 96.3 in Group A and 85.9 in Group C. Defecation in Group B was significantly lower than either in Group A $(p<.01)$ or in Group C ( $\mathrm{p}<.02$; two-tailed tests). Scores for Groups $A$ and $C$ did not differ significantly.

Significant group differences in changes in body weight over the 10 experimental days were found, with Group B registering the greatest mean weight loss $(22.5 \mathrm{~g})$. This value does not differ significantly from the mean weight lost by Group A (18.1 g), but both groups differed significantly from Group $\mathrm{C}$, which showed a mean weight gain of $29.4 \mathrm{~g}$ ( $\mathrm{p}<.001$, two-tailed t tests). 


\section{DISCUSSION}

The subjects in Group A developed a preference for the side of the shuttlebox in which shocks were preceded by a brief tone (preparatory stimulus) and shock-free periods were identified by darkness (safety signal) vs. the side in which neither tones nor darkness had any predictable relation to shock. This finding is consistent with results usually obtained when signaled and unsignaled shock conditions are compared (Lockard, 1963; Perkins, Seymann, Levis, \& Spencer, 1966). But the finding that Group B spent even more time on the safety signal side, despite the fact that the tone was not available as a preparatory stimulus for this group, indicates that a preparatory stimulus does not necessarily increase the relative attractiveness of situations in which inescapable shock is encountered. In fact, preference for the $\mathrm{S} / \mathrm{P}$ vs. the NS/NP side in Group A may have been due to the presence of the safety signal on the preferred side and not to the role played by the tone as a preparatory stimulus.

The results of Group C, for which the safety signal was available on both sides of the shuttlebox, more clearly elucidate the role of the preparatory stimulus. In this group, the inclusion of the tone as a preparatory stimulus on one side of the shuttlebox caused a marked preference for the opposite side. This finding is consistent with expectations based on the interpretation of the preparatory stimulus as a Pavlovian fear elicitor, escape from which some investigators have reported to be reinforcing (Kalish, 1954; McAllister \& McAllister, 1962). Casual observation of reactions to the shocks in Group $\mathrm{C}$ revealed more squealing and jumping in response to the shocks on the S/P than on the S/NP side. Such behavior is also consistent with the view that a preparatory stimulus acts like a Pavlovian fear elicitor. While Badia, DeFran, and Lewis (1968) reported that a preparatory stimulus inhibited vocalization to shock, direct comparison with our study is difficult since our safety signal defined periods completely free of both tones and shocks.

The lowest defecation scores occurred in Group B. While darkness was a safety signal for this group only on one side of the shuttlebox, this is the only group in which the tone never served as a preparatory stimulus. Group C, which encountered the safety signal on both sides, defecated somewhat less than did Group A, which was exposed to similar contingencies except for the presence of darkness as a safety signal on only one side.

If defecation is assumed to be an index of fear, the conclusion that a safety signal is the crucial variable in reducing overall fear may not appear to be consistent with the significantly greater defecation scores obtained for Group C than for Group B. However, our interpretation is that defecation may occur primarily in response to acute fear elicited by the preparatory stimulus, rather than resulting from "chronic" fear associated with the absence of the preparatory stimulus. According to this interpretation, more acute fear elicitations occurred in Groups $\mathrm{A}$ and $\mathrm{C}$, since the tone was a warning stimulus on one side of the box for both groups. For Group B, however, the tone was never an acute fear elicitor, since the preparatory stimulus was omitted from both sides of the shuttlebox.

The weight-change data more directly support the interpretation that a safety signal will reduce overall, or chronic, fear levels: only Group $\mathrm{C}$ gained weight during the experiment, while Groups A and B, with safety available only on one side, lost equal amounts of weight.

Another strategy used to separate the effects of a safety signal vs. a preparatory stimulus was reported by Badia and Culbertson (1972). Their design also employed two stimuli: a brief tone (CS) signaling inescapable shock, and a visual stimulus correlated with signaled-shock segments of the session. While shock frequency was constant throughout the sessions, a barpress response produced the correlated visual stimulus (CO) for 3-min periods during which shocks were always signaled by the tone CS. These conditions produced rapid acquisition. During "extinction," with the shock schedule still in effect, responding reinforced by the $\mathrm{CO}$ alone was most resistant to extinction; responding which produced either the CS alone, or neither CS nor CO, extinguished rapidly. These authors apply a safety signal analysis to their results. They argue that, during training, since the $\mathrm{CO}$ in the absence of the CS identified shock-free periods, the $\mathrm{CO}$ may have acquired reinforcing properties which later maintained responding during extinction. In our $\mathrm{S} / \mathrm{P}$ condition, presence of the light between tone-shock presentations might also be interpreted as an additional safety signal. However, in our design, darkness identified long periods completely free of tones and all shocks, while the light was a danger signal which discriminated periods during which tone-shock pairings occurred. Thus, the safety signal properties of the light alone should not have been as fear-inhibiting in our $S / P$ condition as was the $C O$ in the Badia et al. experiment. While it is difficult to argue that the light in the absence of the tone in our $S / P$ condition had no fear-inhibiting properties, our data are consistent with the interpretation that acute fear produced by the tone was sufficiently intense to override any fear-inhibiting effect the light alone may have had. Thus, it could be argued that Group $\mathrm{C}$ avoided the $\mathrm{S} / \mathrm{P}$ side because of the acute fear elicited by the tones and despite any fear inhibition conceivably produce by the light-alone periods.

To return to the Badia et al. study, when barpressing produced the CS alone, extinction occurred rapidly. We would argue that rapid extinction occurred not because the response failed to produce the safety signal ( $\mathrm{CO}$ ) but because it produced an aversive stimulus, the CS.

Preference for the S/NP side (vs. the S/P side) in Group $\mathrm{C}$ of the present experiment may reflect another 
process in addition to the acquired aversiveness of the preparatory stimulus. To the extent that subjects in the $\mathrm{S} / \mathrm{P}$ condition did try to make some coping response as a way of preparing for the shock, such coping responses were immediately punished by shock. The punishment of coping behavior has been shown to be especially stressful in rats (Weiss, 1971). Accordingly, the subjects in Group $\mathrm{C}$ might prefer the S/NP side, since the absence of a preparatory stimulus on that side precludes the elicitation of punishable coping responses.

The results of this study generally support the conclusion that signaled shock is preferred to unsignaled shock because, in the former condition, the absence of the preshock signal acts like a safety signal. Contrary to the preparatory response hypothesis, it is also conciuded that a warning stimulus is not a condition that animals seek to maintain; rather, they seek to avoid it (other things being equal), as one might predict on the basis of the known fear-inducing and behavior-disrupting properties of such stimuli.

\section{REFERENCES}

Badia, P., \& Culbertson, S. The relative aversiveness of signalled v. unsignalled escapable and inescapable shock. Journal of the Experimental Analysis of Behavior, 1972, 17, 463-471.
Badia, P., Culbertson. S., \& Lewis, P. The relative aversiveness of signalled vs. unsignalled avoidance. Joumal of the Experimental Analy sis of Behavior, 1971, 16, 113-121.

Badia, P., DeFran, R. H., \& Lewis, P. CS-US interval and suppression of unconditioned vocalization to shock: Associative or nonassociative. Psy chonomic Science, 1968, 13 , 269-270.

Kalish, H. I. Strength of fear as a function of the number of acquisition and extinction trials. Joumal of Experimental Psy chology, 1954, 47, 1-9.

Lanzetta, J. T., \& Driscoll, J. M. Preference for information about an uncertain but unavoidable outcome. Journal of Personality and Social Psy chology, 1966, 3, 96-102.

Lockard, J. R. Choice of a warning signal or no warning signal in an unavoidable shock situation. Journal of Comparative \& Phy siological Psy chology, 1963, 56, 526-530.

McAllister, W. R. \& McAllister, D. E. Postconditioning delay and intensity of shock as factors in the measurement of acquired fear. Journal of Experimental Psychology, 1962, 64, 110-116.

Perkins, C. C., Jr. An analy sis of the concept of reinforcement. Psy chological Review, 1968, 75, 155-172.

Perkins, C. C., Jr., Seymann, R. G., Levis, D. J., \& Spencer, H. R., Jr. Factors affecting preference for signal-shock over shock-signal. Journal of Experimental Psychology, 1966, 72, 190-196.

Seligman, M. E. P. Chronic fear produced by unpredictable electric shock. Joumal of Comparative and Physiological Psy chology, 1968, 66, 402-411.

Weiss, J. M. Somatic effects of predictable and unpredictable shock. Psy chosomatic Medicine, 1970, 32, 397-408.

Weiss, J. M. Effects of punishing the coping response (conflict) on stress pathology in rats. Journal of Comparative and Physiological Psy chology, 1971, 77, 14-21.

(Received for publication September 30, 1974; revision accepted January 15,1975 .) 